\title{
Prominence and Engagement: Different Mechanisms Regulating Continuance and Contribution in Online Communities
}

\author{
Jungwon Kuem ${ }^{\mathrm{a}}$, Lara Khansa $\mathbb{D}^{\mathrm{b}}$, and Sung S. Kim ${ }^{\mathrm{c}}$ \\ aDepartment of Information Technology Management, School of Business, State University of New York- \\ Albany, Albany, New York, USA; 'Department of Business Information Technology, Pamplin College of \\ Business, Virginia Tech, Blacksburg, Virginia, USA; 'Department of Operations and Information Management, \\ Wisconsin School of Business, University of Wisconsin-Madison, Madison, Wisconsin, USA
}

\begin{abstract}
Online communities have suffered from their members' intermittent, dormant, or nonexistent participation. We propose that prominence, which refers to the salience of community members' psychological proximity to their community, differs from the engagement construct, which denotes a psychological dedication to behave prosaically toward other community members. Whereas engagement has been increasingly examined as a driver of online community behavior, the role of prominence has received a minimal amount of attention in the literature. Drawing on self-determination theory, we developed a framework that proposes the prominence construct as a phenomenon distinctive from engagement in its nature, formation, and behavioral outcomes. Our findings based on two studies indicate that the proposed model with prominence performs considerably better than the existing model with only engagement. Our conceptual model contributes to Information Systems research by laying a strong theoretical foundation to differentiate between the behavioral paths of the autonomous prominence construct and its controlled engagement counterpart.
\end{abstract}

\section{KEYWORDS}

Prominence; engagement; online communities; participation continuance; online contribution; autonomy; relatedness; knowledge self-efficacy; self-determination

\section{Introduction}

Online communities have become the de facto medium by which people of all ages meet virtually for various reasons, including discussing subjects important to them $[36,55,85]$, sharing know-how with one another $[3,4,16,34,36,46,55]$, and reviewing products and services to inform and help others $[34,43,53,69]$. The repositories of information that these online communities host need constant feeding with reliable and up-to-date information; otherwise, they are of diminishing value to their members. Consequently, online communities are only as good as their members' contributions [31, 69]. Unfortunately, online communities have suffered from their members' sporadic or non-participation, shortcomings partly attributed to their members' losing their motivation to contribute and becoming less engaged with the community $[10,34,36,55]$. Within the information systems (IS) literature, researchers on online communities have looked extensively into the

CONTACT Lara Khansa larak@vt.edu Department of Business Information Technology, Pamplin College of Business, Virginia Tech, 1046 Pamplin Hall (0209), Blacksburg, VA 24061

(4) Supplemental data for this article can be accessed on the publisher's website. 
motives behind online community members' voluntary knowledge contributions $[9,34$, $36,55,72,84,95]$. Specifically, research into online communities has focused on strategies to engage members and encourage their collaboration in various community contexts [26, $29,41,86]$. This literature has emphasized the importance of engagement, which is key to "delurking" lurkers and turning inactive participants into active knowledge contributors $[17,70]$.

Aside from the difficulty of engaging their members, online communities have faced the equally daunting problem of having to compete with other online information sources in gaining and retaining people's attention [74, 89]. The abundance of online information limits people's attention span and appears to bias their preferences and selections [27, 61, 74]. Thus, for online communities to maintain and increase their membership, they must find ways to remain prominent in their members' thoughts and feelings [10] and keep them interested and motivated to participate. We define prominence as the salience of the perceived psychological proximity between a community and its members. The more automatically, naturally, and instantly feelings about the online community come to a member's mind, the more prominence it has for its members. What lies at the core of community prominence is the perceived psychological distance between members and an online community - that is the feeling of self-closeness to the online community. ${ }^{1}$

Although prior research paid attention only to either individual members' active contribution to their online communities $[9,34,36,54,55,69,72,83,84,90]$ or online community continuance $[12,48,90]$, little work exists that examined both types of online community behaviors together in an integrative framework. Given the importance of members' continuance and contribution for the overall health of online communities, it is important to understand the drivers of the two behavioral outcomes. In doing so, the discussion mentioned previously suggests that prominence and engagement are the keys to a better understanding of continuance and contribution in the context of online community behavior.

The influence that prominence has on people's behavior has been validated not just in the marketing literature in which brand prominence has been shown necessary for brands to stand out to their loyal customers $[19,28,67]$, but, importantly, in the IS literature as well $[1,10,14,24,45]$. For example, Lee et al. [45] identified a salience bias effect that significantly influences the performance of crowdsourcing contestants and as such could be detrimental to online crowdsourcing platforms. The authors showed that this salience bias leads to overemphasizing and overreliance on explicitly shown information rather than on implicit information that might be more relevant. Similarly, Benlian [10] showed that capturing and retaining users' attention on a website by using prominent personalization cues leads to users' website "stickiness," that is, their likelihood to return and reuse a website after first use [10, p. 228]. Therefore, not only is online community prominence as important as engagement, but both are expected to affect members' behavior [7].

Engagement is known to be a major driver of individuals' behavior in a group setting $[6,33,71]$. This factor is so powerful in online communities that it overshadows even the impacts of satisfaction and self-identity verification that in this context were believed to be the most important factors in knowledge contribution [70]. Although engagement has been increasingly examined in the literature, the role of prominence has received little attention despite its distinctive properties and importance in the context of the online community. Because of their different natures, engagement and prominence are likely to 
drive different types of behavioral outcomes in the context of online community behavior. For example, whereas engagement is said to influence active participation, prominence is expected to relate to staying in an incumbent online community. Equally intriguing are the questions of how the antecedents of prominence differ from those of engagement.

Our goal in this paper is to address the gaps in the literature and investigate the nature, antecedents, and outcomes of prominence and engagement in the context of online community behavior. Drawing on self-determination theory (SDT) [21], we developed a conceptual model that introduces the prominence construct to the traditional behavioral model linking engagement and prosocial behavior in online communities. ${ }^{2}$ Although somewhat related, prominence and engagement are essentially different in their nature, formation, and outcomes. Thus, from a theoretical perspective, the two different processes centering on prominence and engagement should be simultaneously considered for a thorough understanding of online community behavior. This is especially so because missing one of the two essential factors would result in overestimation of the other factor. From a practical standpoint, such an erroneous representation of online community behavior causes practitioners to miss the opportunities required to facilitate their online communities. In general, this research is expected to contribute to IS research by laying a strong theoretical foundation to differentiate between prominence and engagement. Elucidating the different drivers and outcomes of prominence and engagement will offer strategies to designers to make better and more sustainable online communities.

\section{Theoretical Background}

Our goal in this paper is to show that in online communities, prominence differs from engagement in its formation and behavioral outcomes, thus allowing for a more complete characterization of online community behavior. In this section, we start by briefly reviewing the literature on engagement and prominence to characterize their conceptual differences. Then we introduce the overarching theoretical foundation of the paper, that is, SDT, which forms a theoretical framework for differentiating between prominence and engagement in their antecedents and behavioral outcomes.

\section{Engagement and Prominence}

Engagement is defined in the management literature as "employees' willingness to fully invest themselves physically, cognitively, and emotionally into their work roles" [8, p. 111]. In this context, engagement has been studied as a driver of desirable outcomes such as positive job performance, organizational citizenship behavior, employee satisfaction, loyalty, attachment, and sales volume $[6,8,33,71]$. Similarly, in the marketing literature, customer engagement and employee engagement have been two main areas of research interest. Specifically, Kumar and Pansari [44, p. 498] defined engagement as "the attitude, behavior, the level of connectedness (1) among customers, (2) between customers and employees, and (3) of customers and employees within a firm." The overall takeaway from the marketing literature is that customer engagement and employee engagement are in the best interests of an organization and should be encouraged and pursued $[2,11,44,57]$. In the IS literature, online community research has defined engagement as a deep commitment "to undertake prosocial tasks that benefit others in the group" [70, p. 529]. Engagement is deliberate in that members tend to evaluate their 
previous levels of satisfaction with the community and the available resources (i.e., time and effort) they would be willing to invest before deciding whether, and to what extent, to contribute $[34,36,84]$.

Prominence is an equally important construct. It is prevalent in the brand management literature because customers are confronted with products and services that compete for their attention and dollars. In the marketing literature, brand prominence has been described as the brand's loudness or conspicuousness [28] and prominent brands as attention triggers in either positive or negative ways $[19,74]$. We propose that online communities are another context in which prominence is especially meaningful. This is because, even within the same core area of interest, people have several communities from which they can choose to join. Not only is community membership volitional, but equally uncertain is members' engagement and active knowledge contribution after they join. People may be members in several communities concurrently, but they can choose to contribute less to some than to others.

Prominence is not a new concept in the IS literature. It has been implicitly embedded in several key research areas. For example, the prominent placement of sponsored ads in organic searches was shown to result in higher conversion rates [1, 24], just like a prominent advertisement banner might entice people to click on it [78]. Similarly, in online crowdfunding, the prominent placement of borrowers was found to encourage lenders [14, 45]. Overall, prominent placement has been recognized as crucial to gain people's attention. We extended this prominence concept to show not only the importance of prominence in gaining people's attention but also its possibilities as a driver of community members' behavior. Based on the previous discussion, we conceptualized prominence as a parsimonious construct, in and of itself. In general, prominence differs from the engagement construct in its nature, formation, and outcomes; as such, studies in online community behavior need to model it as a standalone construct. We have summarized previous prominence and engagement research in Supplemental Appendix A.

\section{Self-Determination Theory}

Self-determination theory suggests the powerful impact of motivation on human behavior [21]. It posits that intrinsic and extrinsic forms of motivation play an important role in regulating individuals' behavior. Two other types of motivation are (1) identification, which is considered a self-determined form of extrinsic motivation in that individuals identify with an action and personally support it and (2) introjection, which is closely targeted at gaining reputation and status [72]. The importance of both the intrinsic and extrinsic types of motivation in driving participation are highlighted in the online community literature $[9,34,36,52,53,55,69,70,84]$. Specifically, Ma and Agarwal [52] and later Ray et al. [70] specified satisfaction as a general factor representing both intrinsic and extrinsic types of motivation. Moreover, they used both introjection (i.e., self-identity verification) and identification (i.e., community identification). Self-identity verification conveys community members' perception that their fellow members appreciate them for who they truly are [65]. Meanwhile, community identification is fulfilled when individuals believe their personal values and those of the group they belong to are congruent. ${ }^{3}$

Self-determination assesses the degree to which motivation is autonomous, that is, carried out for its inherent satisfactions [21]. According to Deci and Ryan [21]'s definition, being 
autonomous represents the prototypic instance of self-determination. An important premise of SDT is the existence of three types of basic needs - autonomy, relatedness, and competence - that together drive human motivation and should be met to actualize individuals' full potential [21]. SDT suggests that these basic needs are concerned with emanating from the self (autonomy), conveying a sense of closeness (relatedness), and conveying a sense of being in control (competence). Autonomy refers to the need to feel that one's choices and activities are "self-chosen, self-governed, and self-endorsed" [79, p. 106]. Relatedness is the need to feel "a sense of closeness with others" [79, p. 106]. And competence is the "tendency to seek feelings of effectiveness, achievement, and challenge" in one's activities [79, p. 106]. As such, competence implies a form of "mastery," which refers to a person's "avoidance of mediocrity and decrements in performance" [79, p. 106]. In online community research [34, 93], competence and knowledge self-efficacy have been used interchangeably. In fact, competence is a basic need that is essential to knowledge selfefficacy [20]. Therefore, for compatibility with previous studies of online community behavior, in this study we replaced competence with knowledge self-efficacy. ${ }^{4}$ The three basic needs of autonomy, relatedness, and competence drive human motivation and should be met to actualize individuals' full potential [20]. Consequently, it is essential to include these underexamined factors in behavioral models to gain a deeper understanding of online community behavior.

Causality orientations refer to how people adapt and orient themselves to their environments and, in general, their degree of self-determination across many different contexts [20]. In our model, the causality orientations are: (1) autonomous, in which all three basic needs are satisfied; and (2) controlled, in which only competence and relatedness, but not autonomy, are satisfied [20]. Drawing upon SDT, we differentiated between prominence and engagement based on their varying degrees of self-determination. Using this differentiation, we characterized prominence as autonomous, that is, it fulfills all three basic needs. Conversely, among SDT's three basic needs, we expected only the two that relate to and benefit the community to precede engagement, that is, relatedness and self-efficacy. This exclusion of autonomy occurs because it emanates from the self and is driven by selffulfillment. Consequently, its goals may contradict those of the collective. In fact, autonomy has been associated with less desirable outcomes and lower performance [47, 64]. This has also been observed in the realm of open source software (OSS) communities in which the goals of autonomous contributors may not align with those of their communities, that is, maximizing members' contribution levels [72]. Additionally, given that selfidentity verification and community identification are oriented toward others and thus not purely autonomous, they are likely to affect only engagement but not prominence. This differentiation serves as a fundamental theoretical basis for explaining the differing behavioral characteristics of prominence versus engagement. The distinction also justifies the importance of capturing both concurrently in our model of online community behavior.

\section{Research Hypotheses}

Figure 1 illustrates our conceptual model of online community behavior. We intended the proposed model to explain two important aspects of online community behavior, namely, online community continuance and active contribution. Community continuance denotes 


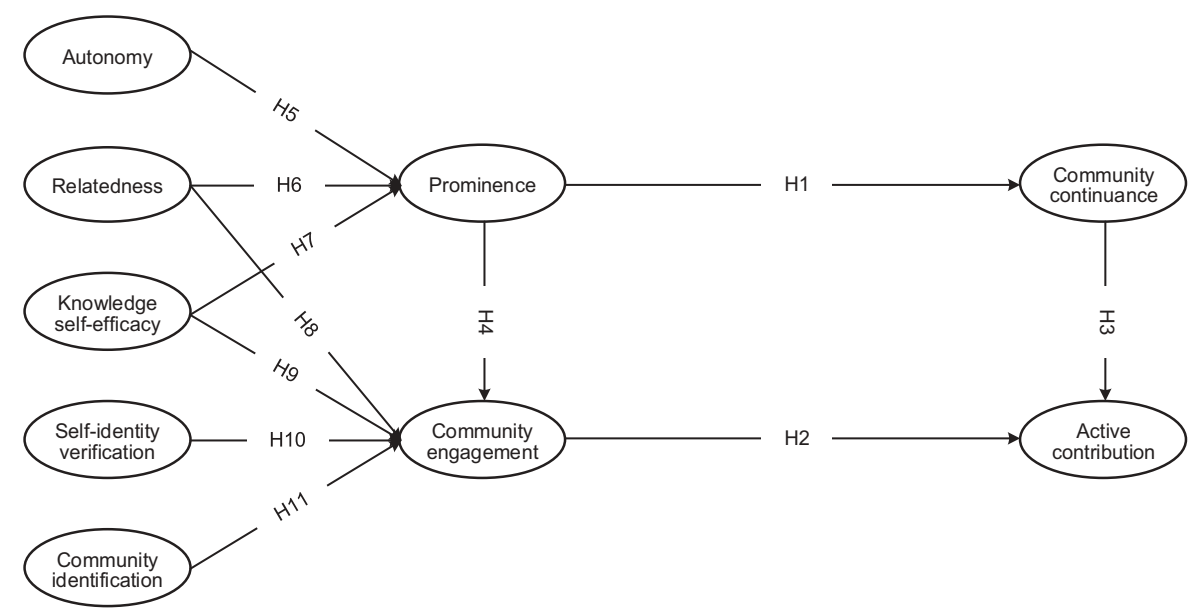

Figure 1. Proposed Model and Hypotheses.

members' intention to passively sustain membership; active contribution signifies members' intention to actively engage in posting knowledge helpful to others in their community. The inclusion of continuance and contribution is grounded in existing theories on lurkers versus active participants [68]. These two constructs represent two critical dimensions of the degree of participation in the community. A key difference between them lies in the need-based and dependence characteristics of continuance - as with lurking, a strong community continuance implies dependence on the utilities and resources of the community. In contrast, contributing does not necessarily imply either need or dependence. Including these two different contributory forms aligns with the literature in seeking to better understand such relationships in an attempt to "delurk" lurkers [17]. In the model, prominence and engagement are identified as intervening variables between antecedents and outcomes.

Five antecedents are also included in the model based on Deci and Ryan's [20, 21] basic five antecedents are also included in the model based on Deci and Ryan's [20, 21] basic needs (i.e., autonomy, relatedness, and knowledge self-efficacy) as well as on findings from research that highlight the beliefs of identity (i.e., self-identity verification and community identification). ${ }^{5}$ Table 1 summarizes how the prominence construct that we introduced in the model differs from the engagement construct in its conceptual definition, antecedents, and outcomes.

\section{Outcomes of Prominence and Online Community Engagement}

Given its closeness to the self, a prominent object gains priority in the mind, so anytime cues about the object are presented, thoughts and feelings about that object are swiftly retrieved [67]. As a result, prominent objects (or brands) remain top of mind [35] and monopolize thoughts and feelings, a situation that in turn results in rejection of alternatives or substitutes [30]. Prior research has shown that prominence is positively associated with "relationshipsustaining behaviors" and the more prominent a community, the more willing its members are to invest time and effort in maintaining an ongoing relationship [67, p. 2]. Similarly, 
Table 1. Differences between prominence and engagement based on SDT.

\begin{tabular}{|c|c|c|}
\hline $\begin{array}{l}\text { Comparison } \\
\text { Dimensions }\end{array}$ & Prominence & Online Community Engagement \\
\hline $\begin{array}{l}\text { Definition in the } \\
\text { information } \\
\text { systems context }\end{array}$ & $\begin{array}{l}\text { - The salience of online community members' } \\
\text { perceived psychological proximity to their com- } \\
\text { munity; the more automatically, naturally, and } \\
\text { instantly feelings about the online community } \\
\text { come to a member's mind, the more promi- } \\
\text { nence it has for its members. }\end{array}$ & $\begin{array}{l}\text { - A deep commitment "to undertake } \\
\text { prosocial tasks that benefit others in the } \\
\text { group" }[70, \text { p. 529]. }\end{array}$ \\
\hline $\begin{array}{l}\text { Causality } \\
\text { Orientation }\end{array}$ & $\begin{array}{l}\text { - Autonomous: Fulfills all three basic needs of } \\
\text { autonomy, relatedness, and self-efficacy. } \\
\text { - Emanates from the self and is driven by self- } \\
\text { fulfillment. }\end{array}$ & $\begin{array}{l}\text { - Controlled: Fulfills relatedness and self- } \\
\text { efficacy, but not autonomy. } \\
\text { Driven by the needs of the collective, } \\
\text { with the goal of benefiting the } \\
\text { community. }\end{array}$ \\
\hline Antecedents & $\begin{array}{l}\text { - } \text { Autonomy } \\
\text { - Relatedness } \\
\text { - Knowledge self-efficacy }\end{array}$ & $\begin{array}{l}\text { - Relatedness } \\
\text { - Knowledge self-efficacy } \\
\text { - Self-identity verification } \\
\text { - Community identification }\end{array}$ \\
\hline Outcomes & - Online community continuance & - Active contribution. \\
\hline
\end{tabular}

because no viable alternative stands out, community members are expected to believe their best interest lie in sustaining their relationship with their prominent community instead of risking a switch to an alternative [30]. In fact, the ease with which thoughts and feelings about a prominent community are brought to mind has been inherently associated with relationship maintenance, a desire for continuity, and repeated behavior [67].

Within the SDT framework, prominence represents an autonomous condition that follows its own desired path and perpetuates the status quo, whereas engagement follows a more controlled process that is specifically targeted at achieving the goals of the community. Because of this intrinsic difference between prominence and engagement, we expect prominence to be associated with a type of direct outcome that favors the status quo (e.g., continuance) versus a rather energetic outcome in the case of engagement (e.g., contribution). Thus,

Hypothesis 1: Prominence has a positive relationship with online community continuance.

Research reported in the online community literature found a positive relationship between engagement and continuance intention. For example, Algesheimer et al. [2] found a positive relationship between community engagement and community continuance in the online brand communities of European car clubs. We also believe that before prominence is introduced into a model, engagement will be similarly related to community continuance. However, after inclusion of prominence, we believe that engagement will be related only to active contribution. This is because prominence and engagement have differential impacts on online community behaviors. Whereas prominence supports the status quo, engagement is known to be associated with prosocial behaviors in formal and informal settings [2, 34, 36, 55, 70, 71]. Ray et al. [70], in particular, showed that engaged members are likelier to contribute knowledge voluntarily to their online 
community. Such engaged individuals are driven to contribute anonymously with no expectation of accolades or rewards because their exertions benefit their communities. Specifically, although prominence is mainly oriented toward reaping short-term benefits, engaged members are willing to exert their time and effort to further grow their online community [70]. For these reasons, engagement, unlike prominence, is expected to directly affect active contribution in the context of online community behaviors. Thus, we propose the following hypothesis:

\section{Hypothesis 2: Online community engagement has a positive relationship with active contribution.}

Although distinct phenomena, continuance and contribution do not occur independently. Members who want to contribute to their community cannot achieve their goals without continuing to visit the same website. Thus, continuance is a necessary condition for contribution in the context of online community behavior. Although continuance does not always lead to contribution, contribution always relies on continuance. Thus, the two factors are believed to correlate significantly with each other. For example, consider the relationship between continued use of mobile phones and data usage. Some phones may sit idle all the time, but all things being equal, data usage is positively related to continued use of mobile phones in an area; that is, the higher the number of mobile phones, the higher the data usage; thus, fewer phones will imply lower overall data usage. This view is also consistent with the resource-based view of online community behavior [84, 95].

Moreover, if members rely heavily on their membership in the community and need to continue it, they are inclined over time to help grow their community [58]. This rationale is supported both theoretically and empirically in the management literature $[60,76]$ in which continuance has often been established as a precursor to contribution. Taken together, online community members who intend to contribute ought also to intend to stay; thus, continuance is an antecedent to actual participation. This is because if members intend to leave the community, they are unlikely to invest their time and effort into contributing knowledge to other members. Thus, we hypothesize:

Hypothesis 3: Online community continuance has a positive relationship with active contribution.

People can form opinions quickly based on simple cues such as familiarity and experience [38]. Thus, all things being equal, the more people are exposed to the same community and become familiar with it, the more they tend to view it favorably. Prominence reflects how easy it is to retrieve thoughts and feelings or the salience of the members' psychological proximity to their community. Such familiarity and experience can encourage members to form positive mindsets about the community that eventually will lead to a high level of engagement. Prominence generally means that a certain community is top of mind [35] and that a person lacks attractive alternatives to that certain community [30]. Such information, albeit brief, could incline members to become committed to their online communities. This process does not necessarily involve deliberate evaluation, but it could come spontaneously. That is, frequent thoughts and feelings about visiting an online community eventually develop into members' naturally 
engaging with the community $[67,80]$. Altogether, we expect prominence will have a positive effect on members' engagement with their online communities.

Hypothesis 4: Prominence has a positive relationship with online community engagement

\section{Antecedents of Prominence and Online Community Engagement}

\section{Antecedents of Prominence}

By its very definition, prominence conveys the salience of community members' perceived psychological proximity between the community and its members. This level of closeness between a community and its members can be achieved when its members perceive it as caring, mindful, and responsive to their needs [21]. According to SDT, the basic needs that are essential to people's well-being and positive states of mind consist of autonomy, relatedness, and competence (i.e., self-efficacy in our model). Given its very connotation of proximity and closeness, the prominence construct is autonomous (i.e., driven by all three basic needs). This oneness between an entity and the people connected to it is colloquially termed flow, which is the ultimate state of enjoyment and happiness. Flow is autotelic, or intrinsically rewarding.

Researchers working in the context of gamification have found compelling evidence linking intrinsic motivation and flow. Liu et al. [50] described immersion in an enjoyable gaming experience as flow, which emanates from flow theory [18, 40, 77]. The authors explained that this flow is experienced when gamers are optimally challenged, that is, enjoyably but not in a cognitively taxing way that causes anxiety. People crave autonomy that allows them to feel in control of themselves [73]. They yearn for objects or experiences that make them feel autonomous. In the online gaming environment, a sense of autonomy has been shown to engulf players with feelings of elation and enjoyment as they teleport to a virtual world [87]. If an object or experience fulfills people's need for autonomy, it becomes seamlessly part of and in close proximity to their self. The more community members crave experiences that satisfy their desire for volition and selfendorsement of their own actions, the closer the community feels to them and the more prominent it is to their self. In other words, the need for autonomy drives community prominence. Thus,

\section{Hypothesis 5: Autonomy has a positive relationship with prominence}

Relatedness or the need to feel connected with others is another basic intrinsic need identified in SDT [21]. In the brand management literature, Morhart et al. [62] showed that when employees are nurtured to develop relatedness to their brand, their brand-based role identity takes on a prominent position within the salience echelon of their employee roles, and it is internalized as the employees' own self-concept [62, p. 126]. Similarly, researchers of event sponsorships have reported in the marketing literature that specific sponsors stand out in the minds of attendees at events only when the attendees are able to establish relatedness between the sponsors and events they attended [79]. The sponsor so identified need not be the actual sponsor but the sponsor most encoded as embedded within and closely related to the event. We also expect a similar connection between 
relatedness and prominence in online communities. Specifically, we propose that a higher perception of relatedness would result in a stronger affective bond with, and commitment toward, the community, in turn making it more prominent in its members' minds. Thus, we propose that a shorter psychological distance between a community and its members, that is, higher relatedness, makes a community more prominent to its members. Thus,

\section{Hypothesis 6: Relatedness has a positive relationship with prominence}

Knowledge self-efficacy represents members' confidence that they have the knowledge and expertise to contribute meaningfully to their community [34, 36, 84]. Research reported in the brand management literature has demonstrated that people's self-efficacy toward a brand, that is, their ability to use their expertise to benefit the brand [25], nurtures "employee brand-self connections, encourages employees to think about the brand, and it engages employees with the brand" [25, p. 138]. Similarly, in the online community literature, Kankanhalli et al. [34] explained that having the skills and the confidence to contribute to the online community is by itself energizing and selfmotivating. Because of the resulting empowerment that knowledge self-efficacy generates, community members are more likely to feel close to the community. Thus, we propose that these feelings of confidence bring the community effortlessly to community members' minds [67].

\section{Hypothesis 7: Knowledge self-efficacy has a positive relationship with prominence}

According to SDT, self-identity verification and community identification are the controlled types of motivation that are not purely autonomous. Thus, we did not expect prominence to be driven by either self-identity verification or community identification. This is because self-identity verification or community identification is ingrained in what others in the community consider desirable, which does not necessarily correspond to what the members themselves desire [22]. Instead, we expected that self-identity verification and community identification are related to engagement, which is controlled but not autonomous.

\section{Antecedents of Online Community Engagement}

Based on SDT, we proposed that engagement is not autonomous but controlled in that it fulfills needs for relatedness and competence (i.e., self-efficacy), but not autonomy; this is because engaged members channel their energy toward activities that benefit and are desired by the larger community and that do not necessarily fulfill the personal needs of the member $[34,72]$. In other words, the degree of member engagement is assessed with respect to the community rather than in a vacuum. Thus, we expect that engagement is determined by relatedness and self-efficacy but not by autonomy. Additionally, SDT further suggests that engagement is significantly linked to self-identity verification and community identification. This phenomenon has been shown to materialize in the context of OSS communities whereby, because of self-identity verification and community identification, members engage in tasks that they might not personally consider intrinsically pleasurable or enjoyable [72]. Taken together, we hypothesize that online community 
engagement is driven by relatedness, self-efficacy, self-identity verification, and community identification. ${ }^{6}$

Relatedness is the need to experience "a sense of mutual respect, caring, and reliance with others" [23, p. 931]. To fulfill this need for belonging, people work hard to earn their membership in a group "to love and care, and to be loved and cared for" [23, p. 231]. As such, striving to engage and connect is a natural consequence of the need to fulfill relatedness. This relationship between relatedness and engagement has been demonstrated in several organizational contexts $[5,13,82]$. The online community context is no exception to this relatedness-engagement relationship. Online support communities represent one such type of online community. These support communities enable their members to deal with their physiological and mental ailments through encouraging them to help others with similar misfortunes. These communities often encourage user engagement with the help of information technology artifacts that increase perceived relatedness. Liu et al. [50] established this strong relationship between relatedness and engagement in this context of online support communities. The authors proposed to use gamification in social support design to encourage users to help others. Yoon and Rolland [88] established a similar link between perceived relatedness and knowledge sharing behavior in virtual communities. All in all, relatedness is expected to drive online community members' engagement. Thus,

\section{Hypothesis 8: Relatedness has a positive relationship with online community engagement}

Knowledge self-efficacy measures the degree of community members' self-confidence in their know-how and ability to contribute unique knowledge to their communities [34]. Wasko and Faraj [84, p. 40] observed that, "knowledge is deeply integrated in an individual's personal character and identity," so the more value members' knowledge has to their communities, the more empowered and confident they will be to engage with their fellow members. This is especially the case in an online community setting in which people only know others by their online personas or, more specifically, by what they perceive their online persona to be. Members with high perceived self-efficacy believe they can help others through their contributions, which makes them happy because people derive great joy and happiness from helping others [84]. In addition, they know that their efforts will make others happy through the help and advice they get. All in all, members with higher self-efficacy are expected to be more engaged. Thus,

Hypothesis 9: Knowledge self-efficacy has a positive relationship with online community engagement.

People adopt a virtual persona of their liking when they join an online community. Some people identify more with their avatar and online community role than they do with their real-life identity. Perhaps they even use their online persona to escape reality and live a life they choose in a parallel virtual world. Because their online identity matters a great deal to them, it becomes crucial for them that the virtual community in which they exist appreciates them for who they truly are. This is more so, given that membership is volitional and members can easily check out and drop their membership permanently, in contrast with real life in which it is harder to check out voluntarily or choose different roles and personas as one pleases. In return for the 
appreciation their virtual persona experiences, they will work hard to preserve the world it flourishes in. As a result, they become more engaged with their community. Self-identity verification is community members' self-assurance that others in the community appreciate their unique skill sets and contributions to the community and think there are no easy substitutes for them. Higher self-identity verification gives members a sense of reassurance that the community appreciates them, which further ignites their drive and increases their engagement. Thus,

\section{Hypothesis 10: Self-identity verification has a positive relationship with online community engagement.}

Community identification is the extent to which members' value system is congruent with that of their community. When members identify with their community, they tend to engage in prosocial behavior with little expectation of reward or reciprocity because such engagement is congruent with their own belief system and is personally meaningful [51]. Community identification has been widely established as a critical driver of customer involvement and engagement [57,63]. For example, Muñiz and Schau [63] showed that even after Apple discontinued its Newton product, members of the Apple brand community remained engaged in helping one another and took pride in their engagement with other Apple fans. McAlexander et al. [57] reported a similarly significant relationship with Jeep owners. In the online community literature, Ma and Agarwal [52] and Ray et al. [70] established a similarly significant relationship between community identification and engagement in the context of online communities. The community identification-engagement relationship is especially meaningful in online communities because in the absence of social ties or prior acquaintance, sharing a common set of convictions is one of the few effective ways to motivate strangers to help one another in an artificial and reward-less environment. Based on the previous arguments, we conjectured a significant relationship between community identification and online community engagement. Thus,

Hypothesis 11: Community identification has a positive relationship with online community engagement.

We conducted two studies to test the research hypotheses. Specifically, in Study 1 we examined the first three hypotheses, all of which are closely related to the key propositions in this paper: prominence and engagement are distinguishable, and these factors lead to distinct outcomes. In Study 2, we tested the entire model, including the 11 research hypotheses we have proposed in this paper. These multiple studies were conducted in different research contexts, a tactic expected to further establish the generalizability of our findings.

\section{Study 1}

We initially conducted a preliminary cross-sectional study to evaluate the first four hypotheses. These hypotheses were evaluated based on data collected from 152 users of Instagram. 


\section{Method}

\section{Research Setting}

We chose Instagram as our research context because it is one of the most popular social networking websites after Facebook [75]. Instagram users have been shown to be more engaged and committed than their Facebook, Twitter, and Snapchat counterparts [69]. Moreover, given the focus of Instagram on nontextual content (e.g., photos and short videos), its users are likelier than others to be influenced by quick and intuitive thought processes. Thus, we considered Instagram appropriate as a research setting to study both prominence and engagement in the context of online community behavior.

\section{Data Collection}

For our data collection, we used a nationwide online panel maintained by a market research firm. We included Internet users who had visited Instagram within the last year. We randomly chose 500 U.S.-based members from the panel pool and then sent each one of them an e-mail message that included a link to our Web-based survey. We received responses from 192 members, yielding a response rate of 38.4 percent. We then found that only 152 , that is, about 79.1 percent of the initial respondents, actually had experience with Instagram. The respondents had a median age of 34, and 55 percent were female. We checked response bias by comparing the respondents and nonrespondents to the survey but found no significant differences in terms of age and gender.

\section{Measures}

Supplemental Appendix B contains the specific items included in Study 1. The scales we used were adapted from previous studies. We measured prominence with four items adapted from Park et al. [67], and community engagement with three items from Ray et al. [70]. As one of the two outcome variables in this study, community continuance was measured with three items adapted from Limayem et al. [48]. We measured active contribution, which is the other outcome variable in this study, by using two items from $\mathrm{Ma}$ and Agarwal [52] and an additional item we created. Meanwhile, we used three items to measure fashion involvement, which refers to how seriously a person takes his or her style of dress [81]. Fashion involvement is thought to have little to do with online community behavior, thus it can be used to assess common method variance [56]. As a control variable, satisfaction was measured with four items adapted from Kim and Son [39] and Ray et al. [70]. We also adapted single-item controls for individual characteristics from Ray et al. [70]. As such, this study included four individual characteristics, that is, gender, age, frequency of visits to the online community, and length of tenure.

\section{Results and Discussion}

We examined the measurement model through a confirmatory factor analysis (CFA) by using LISREL 8 [32]. The measurement model consisted of five reflective constructs as well as four single-item control variables. Supplemental Appendix C shows the results of the CFA as well as the descriptive statistics, reliabilities, and correlations of the variables. We found that the measurement scales were psychometrically satisfactory with adequate 
levels of reliability and convergent and discriminant validity. In addition, common method bias was not considered a threat to the validity of our findings.

We analyzed the proposed model by using LISREL 8 [32]. This model includes only the first four hypotheses while the effects of control variables on the outcome variables are explicitly taken into account. Figure 2 shows the results of the model with the statistical significance of paths. The model shows excellent fit $\left[\chi^{2}(162)=193.00(p<0.05)\right.$, RMSEA $=0.036, \mathrm{CFI}=0.99, \mathrm{NFI}=0.96, \mathrm{NNFI}=0.99$, AGFI $=0.85$.$] . The model explained$ 29 percent of the variation in engagement, 48 percent in continuance, and 40 percent in contribution. As shown in Figure 2, prominence has a significant impact only on continuance $(0.23, \mathrm{p}<0.05)$ (Hypothesis 1 supported), whereas engagement is positively associated only with contribution $(0.50, \mathrm{p}<0.001)$ (Hypothesis 2 supported).

These results were exactly consistent with our earlier hypotheses that prominence and engagement have differential impacts on behavioral outcomes. In addition, the results indicated that continuance played an important role in determining contribution in the context of Instagram use $(0.19, \mathrm{p}<0.10)$. Consistent with our hypothesis, this positive relationship was statistically significant at the level of 0.05 (one-tailed) (Hypothesis 3 supported). Moreover, satisfaction was found to be a significant determinant of continuance $(0.50, \mathrm{p}<0.001)$ but did not affect contribution.

Interestingly, none of the other control variables was significant in explaining the two behavioral outcomes. These findings are taken as additional evidence of the efficacy of our model as a tool for describing online community behaviors. Finally, we found that prominence had a significant effect on engagement $(0.54, \mathrm{p}<0.001)$ (Hypothesis 4 supported).

In general, the findings of this study point to a systematic pattern of relationships among prominence, engagement, and their outcomes in the context of online community behavior. Although this study suggests the differential impacts of prominence and engagement on continuance and contribution, it has limitations that at this point preclude

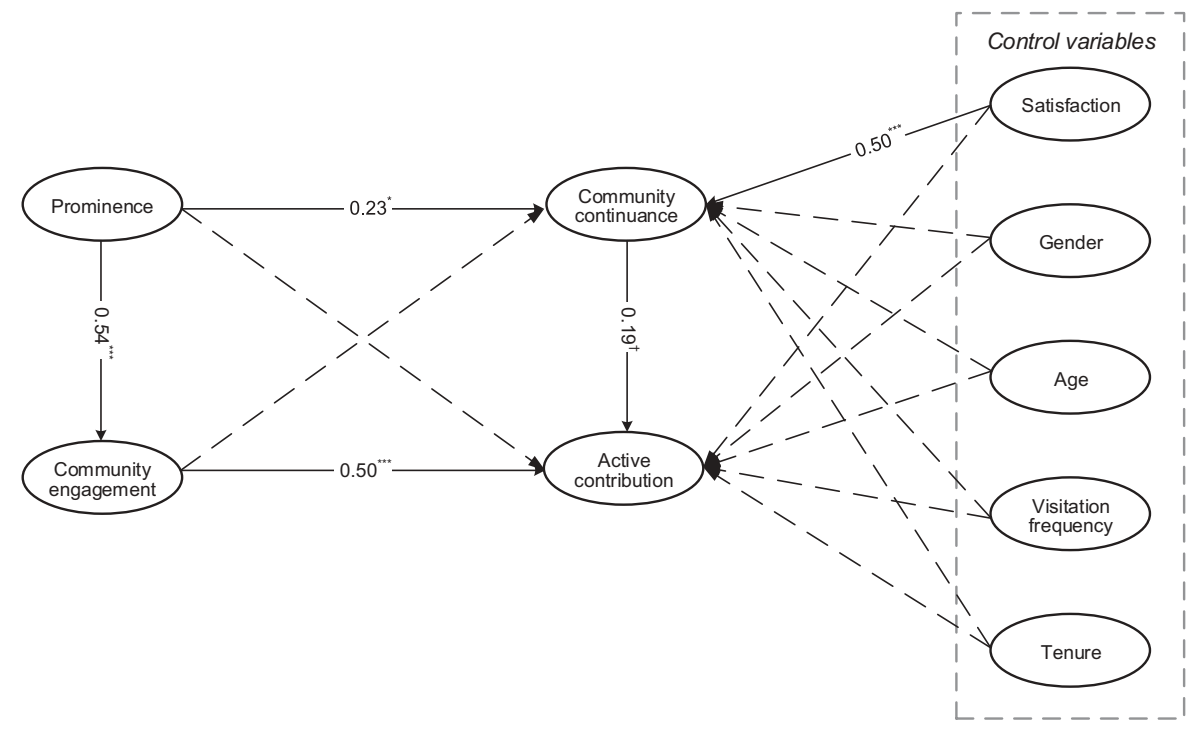

Figure 2. Results of the proposed model. 
further generalization of our conclusions. First, it is unclear whether a longitudinal setting would corroborate out findings in this study. Second, this study focused on an online networking community, and we are unsure if the model would continue to work well in other online community contexts. Lastly, in this study we did not take into account the antecedents of prominence and engagement; consequently, we are still not certain about how their antecedents differently cause these two psychological factors. To address these limitations, we needed an additional study.

\section{Study 2}

Our second study was intended to (1) identify the antecedents of prominence and engagement, (2) further establish the generalizability of our findings through a different research setting, and (3) reduce common method bias by reexamining the relationships of the two factors with their outcomes within a longitudinal context. All of the 11 hypotheses were tested by using data collected from 373 users of online discussion forums.

\section{Method}

\section{Research Setting}

In Study 2, we examined community members' reactions to online discussion forums. Online discussion communities - where members, who for the most part are strangers, exchange professional, personal, or other general interests asynchronously - have often been the target of prior research $[52,68,84]$. Thus, these communities are an ideal setting for us to compare our results with those of these past studies. Our study was not specific to a certain online discussion community but instead covered a broad set of such communities. This general approach allowed us to control for website characteristics and regulatory practices that may affect individuals' perceptions and behavior related to online communities.

\section{Data Collection}

Data for this research were gathered using two Web-based surveys designed to measure research variables and other information related to individuals' use of an online community. The first survey included control variables as well as research variables except behavioral outcomes. This second survey contained two outcome variables, that is, continuance and contribution. We used a nationwide online panel, maintained by a market research firm, to collect our data. We considered Internet users who had visited any online discussion community within a year. For the first survey, we randomly chose 2,000 U.S.-based members from the panel pool and sent each of them an e-mail message that included a link to our Web-based survey. We received responses from 782 members, a response rate of 39.1 percent. We then found that only 492, that is, about 63 percent of the initial respondents, actually had experience with online discussion communities. Respondents reported using a variety of online discussion communities oriented toward hobbies, politics, sports, health support, and technology-related interests. We deleted 16 responses from the 492 because they did not fit well with our conceptualization of online discussion forums (e.g., Facebook, LinkedIn). As a result, we collected a total of 476 usable responses in the first survey. The 
respondents' median age was 39, and 52 percent were female. We checked response bias by comparing the respondents and nonrespondents of the first survey, but found no significant differences in terms of age and gender. We sent e-mail messages with a link to the follow-up survey to the 476 respondents to the first survey. The second survey was sent four weeks after the first. In the second survey, we collected 373 responses, which represented a response rate of 78 percent. We found that the median age of the respondents was about 39 , and 54 percent were women. No significant differences were found between the respondents and nonrespondents to the second survey. Finally, our data analysis used the completed responses from the 373 panel members who participated in both surveys.

\section{Measures}

The items used in Study 2 are shown in Supplemental Appendix B. The items in Study 2 included all of the items used in Study 1 as well as extra items for measuring antecedent variables and website characteristics. We measured autonomy with four items from [79]. We measured relatedness with four items adapted from [79], and knowledge self-efficacy with three items adapted from Ray et al. [70]. We measured self-identity verification by drawing three items from Ray et al. [70]. Three items drawn from Ray et al. [70] were used to measure community identification. We adapted single-item controls for website characteristics from Ray et al. [70]. Specifically, we included five single-item measurements of website characteristics, that is, past postings, user moderation, profile depth, virtual compresence, and regulatory practices. Past postings were related to a website feature that lets members find a particular user's previous messages; user moderation refers to a website feature that allows members to evaluate others' messages; profile depth is concerned with whether a website allows members to create a public profile; virtual copresence indicates a website feature that reveals whether members are currently online or offline; and lastly, regulatory practice is concerned with whether website administrators can ban or penalize disruptive messages.

\section{Results and Discussion}

The measurement model consisted of 10 reflective constructs and nine single-item control variables. Supplemental Appendix D shows the results of CFA as well as descriptive statistics, reliabilities, and correlations of the variables. Our measurement scales were shown to be psychometrically satisfactory with adequate levels of reliability and convergent and discriminant validity. Furthermore, we found that that common method bias was not a threat to the validity of our findings.

We tested two alternative structural models. The first model, or Model 1, centered on engagement as an intervening variable between three antecedents (i.e., knowledge selfefficacy, self-identity verification, and community identification) and two outcomes (i.e., continuance and contribution). In Model 1, engagement played a central role within the conceptual framework. Meanwhile, the second model, Model 2, which represents the proposed model, added prominence and its antecedents (i.e., autonomy and relatedness) onto what Model 1 had already taken into account. In Model 2, all of the paths between the antecedent and intervening variables were allowed to be free. The same was true for the paths 
between the intervening and outcome variables. The control variables included in both models were satisfaction, four demographic variables, and five website characteristics.

We used LISREL 8 to analyze the two structural models [32]. Table 2 shows the results of the models, including fit statistics, path estimates, and squared multiple correlations (SMCs). As shown in Table 2, the first alternative model showed satisfactory fit $\left[\chi^{2}(330)=711.01(p<0.001)\right.$, RMSEA $=0.056, \mathrm{CFI}=0.98, \mathrm{NFI}=0.96$, NNFI $=0.97, \mathrm{AGFI}=0.84]$. Figure 3 shows the specifications of Model 1 and the results of the structural equation model. Consistent with Ray et al. [70], the three antecedents of engagement were found statistically significant. In general, these results further supported the model by Ray et al. [70] and specifically confirmed the key role of engagement as an intervening variable between its antecedents and outcomes.

We subsequently tested Model 2, which was our proposed model. Despite the greater complexity of the model in comparison with Model 1, Model 2 generally fit the data better than Model $1\left[\chi^{2}(708)=1337.69(\mathrm{p}<0.001)\right.$, RMSEA $=0.049$, CFI $=0.99$, NFI $=0.97$, $\mathrm{NNFI}=0.98$, AGFI $=0.81]$. As we expected, we found that prominence was influenced by autonomy (0.43, p $<0.001)$, relatedness $(0.25, \mathrm{p}<0.001)$, and knowledge self-efficacy (0.17, $\mathrm{p}<0.01)$. However, self-identity verification and community identification did not influence prominence. This suggests that identity-related factors contribute to the

Table 2. Results of Structural Equation Modeling

\begin{tabular}{|c|c|c|c|c|c|c|c|}
\hline \multirow{2}{*}{$\frac{\text { Effects }}{\text { Causes }}$} & \multicolumn{3}{|c|}{ Model 1} & \multicolumn{4}{|c|}{ Model 2 (Proposed model) } \\
\hline & OCE & OCC & $A C$ & PR & OCE & OCC & $A C$ \\
\hline AGE & -0.05 & 0.04 & $0.11^{*}$ & -0.06 & -0.01 & 0.06 & $0.09^{*}$ \\
\hline GEN & 0.02 & 0.05 & -0.05 & -0.06 & 0.03 & 0.06 & -0.07 \\
\hline FR & $0.12^{* *}$ & $0.20^{* * *}$ & $0.15^{* *}$ & 0.05 & $0.08^{*}$ & $0.21^{* * *}$ & 0.02 \\
\hline TEN & -0.07 & $0.13^{* *}$ & 0.04 & $008^{*}$ & $-0.08^{*}$ & $0.11^{*}$ & -0.06 \\
\hline $\mathrm{RP}$ & $-0.13^{* *}$ & $0.10^{*}$ & 0.02 & -0.06 & $-0.11^{* *}$ & 0.10 & -0.04 \\
\hline VC & -0.02 & $-0.11^{*}$ & -0.01 & 0.02 & -0.02 & $-0.11^{*}$ & 0.05 \\
\hline PD & 0.01 & 0.07 & 0.02 & 0.02 & 0.00 & -0.07 & -0.02 \\
\hline UM & 0.01 & 0.08 & 0.07 & 0.04 & 0.01 & 0.07 & 0.02 \\
\hline PP & 0.00 & 0.00 & 0.01 & -0.05 & 0.00 & 0.00 & 0.02 \\
\hline SAT & $0.22^{* * *}$ & $0.29^{* * *}$ & 0.06 & 0.07 & $0.15^{* *}$ & $0.29^{* * *}$ & $-0.15^{* *}$ \\
\hline $\mathrm{AU}$ & & & & $0.43^{* * *}$ & 0.08 & & \\
\hline REL & & & & $0.25^{* * *}$ & $0.21^{* * *}$ & & \\
\hline KSE & $0.27^{* * *}$ & & & $0.17^{* *}$ & $0.14^{*}$ & & \\
\hline SIV & $0.28^{* * *}$ & & & -0.07 & $0.16^{*}$ & & \\
\hline CID & $0.29^{* * *}$ & & & 0.09 & $0.24^{* * *}$ & & \\
\hline PR & & & & & $0.16^{* *}$ & $0.16^{*}$ & 0.10 \\
\hline OCE & & $0.21^{* * *}$ & $0.46^{* * *}$ & & & 0.06 & $0.28^{* * *}$ \\
\hline OCC & & & & & & & $0.61^{* * *}$ \\
\hline $\mathrm{R}^{2}$ & 0.73 & 0.42 & 0.37 & 0.66 & 0.79 & 0.42 & 0.60 \\
\hline \multicolumn{8}{|c|}{ Model Fit } \\
\hline$x^{2}$ & & 711.01 & & \multicolumn{4}{|c|}{1337.69} \\
\hline d.f. & & 330 & & \multicolumn{4}{|c|}{708} \\
\hline RMSEA & & 0.056 & & \multicolumn{4}{|c|}{0.049} \\
\hline $\mathrm{CFI}$ & & 0.98 & & \multicolumn{4}{|c|}{0.99} \\
\hline $\mathrm{NFI}$ & & 0.96 & & \multicolumn{4}{|c|}{0.97} \\
\hline NNFI & & 0.97 & & \multicolumn{4}{|c|}{0.98} \\
\hline AGFI & & 0.84 & & \multicolumn{4}{|c|}{0.81} \\
\hline
\end{tabular}

Notes: $\mathrm{n}=373$.

$\mathrm{AGE}=$ age; $\mathrm{GEN}=$ gender; $\mathrm{FR}=$ visitation frequency; TEN = tenure; $\mathrm{RP}=$ regulatory practices; $\mathrm{VC}=$ virtual copresence; $\mathrm{PD}=$ profile depth; $\mathrm{UM}=$ user moderation; $\mathrm{PP}=$ past postings; $\mathrm{SAT}=$ satisfaction; $\mathrm{AU}$ = autonomy; $\mathrm{REL}=$ relatedness; $\mathrm{KSE}=$ knowledge selfefficacy; SIV = self-identity verification; CID = community identification; PR = prominence; OCE = online community engagement; $\mathrm{OCC}=$ online community continuance; $\mathrm{AC}=$ active contribution

${ }^{*} \mathrm{p}<0.05 ;{ }^{* *} \mathrm{p}<0.01$; ** $\mathrm{p}<0.001$ (two-tailed) 


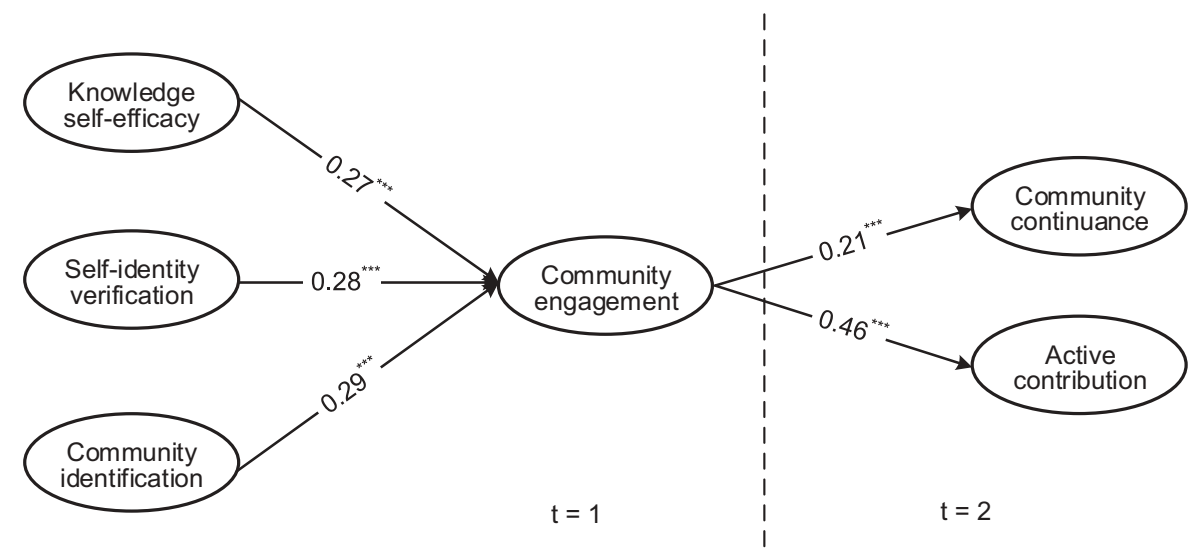

Figure 3. Results of model 1.

formation of engagement but not necessarily to the formation of prominence. After including prominence as an antecedent of engagement, we found autonomy was no longer a significant determinant of engagement $(0.08, p=n s)$. Nevertheless, the other four antecedents remained significant in determining engagement. Besides, we also found that as expected, prominence had a positive relationship with engagement $(0.16, \mathrm{p}<$ 0.01). One interesting result of Model 2 was that after prominence was taken into account, engagement was no longer a significant determinant of continuance $(0.06, p=n s)$. The results indicate that as expected, continuance had a significant effect on contribution $(0.61$, $\mathrm{p}<0.001)$. We also found that active contribution was still a function of engagement $(0.28, \mathrm{p}<0.001)$, even after controlling for online community continuance. However, prominence did not have a direct impact on active contribution $(0.10, \mathrm{p}=\mathrm{ns})$.

Taken together, this study strongly supported our assertions that prominence and engagement differ substantially in terms of their nature, antecedents, and consequences. ${ }^{7}$ Figure 4 depicts the results of the proposed model but only with its significant

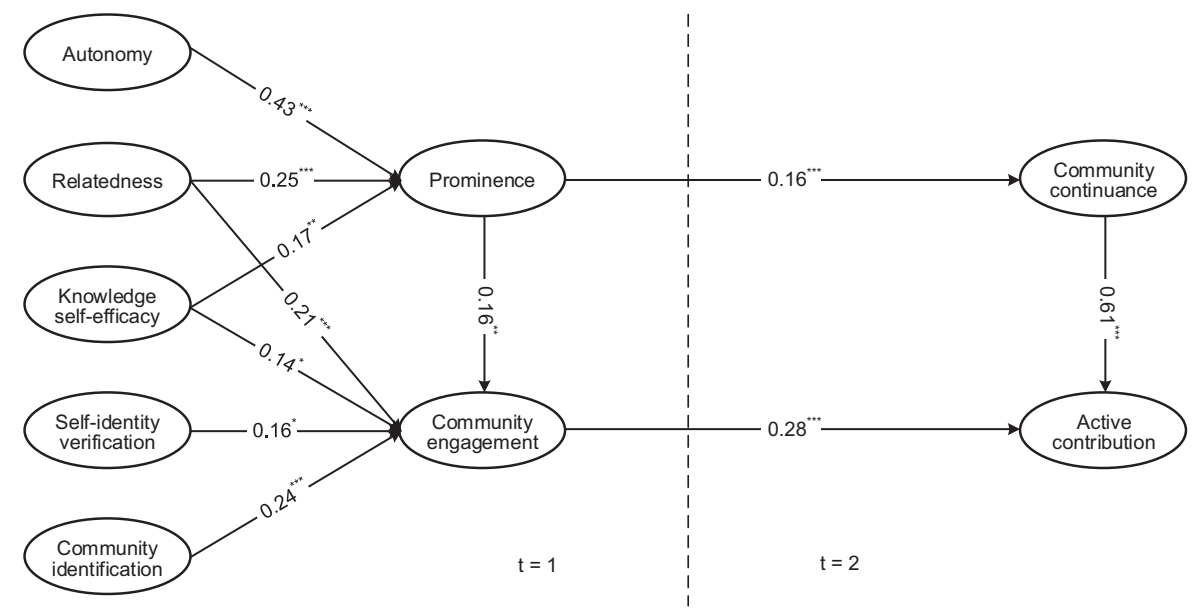

Figure 4. Results of model 2 (proposed model). 
relationships at the level of 0.05 . In addition, all of the 11 hypotheses proposed in this study received empirical support (Hpothesis 1-Hypothesis 11 supported).

Finally, we examined the effects of the 10 control variables on four endogenous variables. Our results indicated that 9 of 40 relationships were statistically significant (22.5 percent), which implies that these controlled effects were not random. Some controlled effects were substantial and thus deserved attention. In particular, the effect of satisfaction on continuance was found highly influential $(0.31, \mathrm{p}<0.001)$. This result is consistent with prior research as well as with Study 1 that substantiated the powerful role of satisfaction in regulating continued use of an online service [39, 48, 94]. In general, although our research variables were effective in describing individual members' reactions to an online discussion community, additional factors such as satisfaction are still indispensable for a complete accounting of online community behavior.

\section{Discussion}

The main objective of this paper was to propose and develop the prominence construct in the online community context and demonstrate that it adds value to IS research beyond that of the engagement construct [70]. We used SDT as the theoretical foundation of our paper to link the motivations of online community members' behavior to their behavior in the community. We conducted two studies and tested our hypotheses against data collected from 152 and 373 actual members of online communities. Our results provide strong support for our proposed model. Specifically, we showed that prominence differs from engagement in its nature, formation, and outcomes. In addition, our findings indicate that prominence, which is determined partly by autonomy, affects continuance, whereas online community engagement, which is influenced partly by self-identity verification, community identification, and prominence, leads to active contribution. Overall, this paper contributes significantly to the IS literature by showing the importance of accounting for prominence, alongside engagement, to provide a more complete and precise depiction of online community behavior.

\section{Theoretical Contributions}

Our paper contributes to the online community literature in several important ways. To start with, this is the first IS paper to develop and validate a model of online community behavior that integrates the two very different, yet complementary, engagement and prominence constructs. To explain online community behavior such as continuance and contribution, prior research focused on antecedents associated with a controlled, deliberative, and analytic process. Examples of such antecedents are engagement, community identification, and self-identity verification $[12,48,52,70]$. However, a minimal amount of attention was given to the construct of prominence, which represents the autonomous and spontaneous process. Our study is meaningful because, drawing on SDT, it sheds light on how prominence can operate simultaneously with engagement to better characterize community behavior. Specifically, the model we have proposed in this paper shows that because of the differences in nature between prominence and engagement, their antecedents and outcomes differ systematically. Thus, eliminating one or the other leads to an incomplete characterization of online community behavior. ${ }^{8}$ 
Second, Ray et al. [70] conceptualized engagement as a powerful driver of contribution $(0.61, \mathrm{p}<0.001)$. Consistent with Ray et al. [70], our study shows that without taking into account prominence, engagement affects contribution $(0.46, \mathrm{p}<0.001)$ as well as continuance $(0.21, \mathrm{p}<0.001)$ (see Figure 3$)$. However, we have also demonstrated that after the introduction of prominence into the model, engagement stopped being a direct determinant of continuance $(0.06, \mathrm{p}=\mathrm{ns})$. Our results appear to conflict with prior research that showed that engagement is a direct antecedent of continued behavior in online communities $(0.46, \mathrm{p}<0.001)$ [15]. Nevertheless, we have demonstrated theoretically and empirically that the direct impact of engagement on continuance is spurious and such a spurious result is caused by the lack of prominence in a model. On the other hand, this research shows a first piece of evidence regarding the impact of prominence on online community behaviors. Specifically, we found that prominence had a direct effect on continuance $(0.16, \mathrm{p}<0.001)$ but not on active contribution $(0.10, \mathrm{p}=\mathrm{ns})$. These findings suggest that whereas prominence regulates some aspects of online community behavior (e.g., continuance), engagement plays an important role in other aspects of online community behavior (e.g., contribution). Overall, this study contributes to IS research by showing how significantly the concept of prominence can change the traditional view of online community behavior that focused exclusively on engagement. It lays a strong theoretical foundation for the differential effects of prominence and engagement on a variety of online community behaviors.

Third, drawing on SDT, we argued that whereas engagement is largely controlled, prominence is autonomous. Because of this difference, prominence and engagement were hypothesized to differ in their formative processes. Specifically, although self-identity verification and community identification significantly characterize engagement, they are not significantly related to prominence. Both of these identity-based measures are rather controlled and deliberate and do not fit well with the autonomous and spontaneous prominence construct. As expected, they were significantly associated with engagement but not with prominence. We have also found that autonomy is not a significant determinant of engagement $(0.07, \mathrm{p}=\mathrm{ns})$. This was expected by our theoretical framework based on SDT; autonomy, a rather autonomous measure reflecting true inner feelings, does not fit well with the controlled nature of engagement. This paper has dissected the antecedents of prominence and has clearly highlighted the formative differences between prominence and engagement in the context of online communities. It significantly contributes to online community research by theoretically and empirically demonstrating how autonomous and controlled aspects of antecedents differently formulate prominence and engagement.

Lastly, although several studies have examined the determinants of contribution [9, 34, $36,54,55,69,72,83,84,90]$ or continuance separately [12, 48, 90], a minimal amount of work has attempted to integrate the two into one coherent model of online community behavior. Community continuance denotes members' intention to passively sustain their membership in the community, whereas active contribution denotes members' intention to actively engage in posting knowledge helpful to others [34, 36, 55, 68, 83]. We have shown that continuance, alongside engagement, is indeed an important determinant of active contribution. More interestingly, we found that the effect of continuance on active contribution $(0.061, \mathrm{p}<0.001)$ is considerably stronger than the effect of engagement on active contribution $(0.028, \mathrm{p}<0.001)$. Thus, to better explain active contribution, we 
should pay more attention to continuance instead of focusing exclusively on engagement. Taken together, our findings suggest that a complete understanding of contribution behavior cannot be acquired without taking online community continuance into account. ${ }^{9}$

\section{Managerial Implications}

Our paper offers many insights for online community moderators and administrators on how to make communities more prominent among their members and keep them engaged. First of all, we found that autonomy is a necessary antecedent of prominence; therefore, members need to feel autonomous as a precondition for the community to become prominent in their minds. Achieving this necessitates flexible technical features that allow members to express their individuality and give them a perception that they have control over choices they wish to make. In addition, we recommend that community administrators be open-minded in regulating members' posts and comments so that any contributions that members provide feel voluntary. Moreover, if members choose to voluntarily increase their participation, they should be given the technical means to do so on their own terms and whenever they please. This means that the community platform should always be available to its members, and any limits to contributions, technical or otherwise, should be minimized.

Meanwhile, self-efficacy was found necessary to both engagement and prominence and therefore, to continuance and contribution. Knowledge can be objective and therefore, easily assessed such as in the context of technical online communities (e.g., the StackOverflow community). Confidence can be boosted with a reward system that recognizes exceptional contributions in number and quality, as evaluated by other members (using IT artifacts such as helpfulness votes) or by moderators and administrators of the online community (using artifacts such as levels of membership). Overall, community design artifacts or online social dynamics can change prominence and engagement, which eventually determine online community behavior.

\section{Limitations and Further Research}

Some limitations of this paper deserve mention. First, we used subjective, as opposed to objective, measures to capture continuance and contribution. Our approach is consistent with the prior literature in online communities, and thus the findings of this paper can be easily compared with past findings $[52,70]$. Nevertheless, the findings of this paper should be reevaluated with the objective measures of behavioral outcomes. Second, our model is rooted in Ray et al. [70], which draws on Ma and Agarwal [52]. As a result, the research and control variables chosen in the present paper are considered generally reasonable. However, we still cannot exclude the possibility that other variables not considered in this paper could affect members' reactions to an online community.

Third, another limitation of this study relates to the relatively high correlations of engagement with other variables in Study 2 ( $\mathrm{rs}>0.70$ ). We evaluated discriminant validity and found that it does not pose any serious problem. Interestingly, in a similar context of online discussion communities, Ray et al. [70] also reported high correlations of engagement with other variables ( $r s>0.70$ ). We suspect that to some extent these high correlations resulted from the specificity of the context examined. For example, in Study 1, in 
which online social networking was examined, the correlations of engagement with other variables were found to be smaller ( $r s<0.70)$. In sum, although successfully established in this research, the discriminant validity of our scales should be further evaluated in other contexts.

Fourth, in this study, we conceptualized prominence as an antecedent of engagement based on the notion that simple cues such as familiarity and experience serve as a basis for the formation of deliberate opinions [37]. Yet it is still possible that deliberate opinions facilitate instant thoughts and feelings; thereby, engagement could be an outcome, as opposed to an antecedent, of prominence. Because of the limitation of the cross-sectional nature of the data, we could not evaluate a causal flow between prominence and engagement. Thus, caution should be exercised in interpreting our results until such a causal precedent is more rigorously established. ${ }^{10}$ Fifth, the outcomes in the second study, which was longitudinal, were measured as behavioral intentions (instead of behaviors) as was the case in the first study, which was cross-sectional. The major reason for using the same intention variables as the outcomes was to establish the close correspondence between Study 1 and Study 2, which would facilitate a thorough comparison between them. Moreover, this longitudinal study helped reduce the unavoidable common method bias inherent in the cross-sectional study. Still, the validity of our model should be further examined through the use of behavioral measures in a longitudinal context.

Sixth, in this study, the concept of competence is replaced with knowledge self-efficacy, which has often been included in traditional models of online community behavior [34, $49,70]$. Although not identical, they are highly correlated in that competence as a human need is essential to self-efficacy. In fact, online community research [34, 93] has treated competence and self-efficacy interchangeably. However, because the two concepts are not exactly the same, caution should be exercised in interpreting our findings. Finally, although our subjective measure of prominence is consistent with the prior literature [67], it may be more accurately captured by using less intrusive techniques, e.g., brain scanning. The self-report measure of prominence is considered acceptable, given the focus of our paper, but our findings should be carefully interpreted until they are empirically confirmed with more precise measurements.

This paper opens fertile avenues for further research. We introduced the relatively new concept of prominence into IS research, and this factor seems to have enormous potential for opening the way to a better understanding of online behavior that is driven by autonomous and spontaneous processes. For example, online gaming is thought to be influenced not only by conscious evaluations of the pros and cons of playing the game in question but also by spur-of-the-moment urges. Such unplanned desires are likely to arise in a variety of settings that include, but are not limited to, online media consumption (e.g., news, music, and video), online shopping, social networking sites, and online gambling. Another interesting avenue for future research is to extend the model by incorporating a new perspective. In particular, a commitment model proposed by Bateman et al. [9] posits that members' participatory behavior such as posting, reading, and moderating messages in online communities is a function of three types of commitment, namely, affective, normative, and continuance. These types of commitment are likely to have significant impact on behavioral outcomes (e.g., continuance, contribution) beyond the variables examined in this paper (e.g., prominence, engagement) [42]. Researchers are 
encouraged to explore these opportunities to extend our proposed model in pursuit of a comprehensive model of online community behavior.

\section{Conclusions}

Although engagement has been introduced in the IS literature as a controlled, deliberate construct that characterizes knowledge contribution in online communities, prominence, its autonomous and top-of-mind counterpart, has not received any attention. Nevertheless, we have shown that prominence is not only complementary to engagement in its depiction of online community behavior but also a necessary antecedent to engagement that has unique characteristics and behavioral outcomes. Online communities continue to permeate every aspect of society and humanity, and they reflect the complex human mind and the products of their members' behavior. We believe that to fully realize the potential of these social structures, researchers in the online community domain and practitioners managing online communities need to build on a better understanding of prominence and engagement when modeling and designing online communities.

\section{Notes}

1. Prominence differs from the psychological proximity [59] construct in two ways. First, unlike Mencl and May [59]'s psychological proximity construct that denotes an actual bond, prominence refers to the salience of a bond, i.e., the extent that the bond is top of mind. Second, according to our definition, prominence is autonomous in that it emanates from the self and serves to fulfill the community member's inherent needs. In the marketing literature, being autonomous has been known to be a central element of brand prominence because when consumers feel in control of their selves and their own decisions, their perceived cognitive and affective memory accessibility about the brand, which is defined as brand prominence, increases [66]. Similarly, prominence of online communities in the context of this paper is autonomous in that it is less affected by extrinsic sources and thus more instantly activated with little effort. On the other hand, conceptually speaking, psychological proximity conveys a lack of autonomy in that it is centered on the object of proximity (e.g., community). We thank Reviewer 3 for pointing out this important distinction.

2. Prior literature used SDT to study continuance and contribution [91, 92]. Although similarly drawing on SDT, our study differs from prior research. This is because our study rooted in SDT highlights the mediating variables of prominence and engagement. Instead of simply describing the antecedents of continuance and contribution, we identify the key mediators (i.e., prominence and engagement) between their antecedents (e.g., autonomy, competence, relatedness) and behavioral outcomes (i.e., continuance and contribution).

3. Self-identity verification and community identification represent, respectively, introjection and identification in the context of online community behavior. Thus, instead of introjection and identification, the community-specific terms, i.e., self-identity verification and community identification, will be used throughout the rest of the paper.

4. A limitation of replacing competence with self-efficacy is acknowledged in the discussion section.

5. Note that our model also included satisfaction, which has both intrinsic and extrinsic characteristics $[52,70]$, and other relevant variables as controls. We did not hypothesize about satisfaction because its relationship with online community behavior has already been established [52, 70, 79].

6. We thank Reviewers 1 and 2 for encouraging us to elaborate on this issue.

7. We examined variance inflation factor (VIF) scores and found that the maximum VIF value under each model was 2.08 , which is well below the commonly used threshold of 5 or 10 . Thus, it is reasonable to argue that multicollinearity should not be a serious concern in this study. 
8. We thank Reviewer 2 for helping us more clearly contrast these two constructs at both conceptual and empirical levels.

9. We thank Reviewer 1 for encouraging us to elaborate on this important issue.

10. We thank Reviewer 3 for pointing out this alternative explanation for our findings.

\section{ORCID}

Lara Khansa (1] http://orcid.org/0000-0001-7305-5190

\section{References}

1. Agarwal, A.; Hosanagar, K.; and Smith, M.D. Do organic results help or hurt sponsored search performance? Information Systems Research, 26, 4 (2015), 695-713.

2. Algesheimer, R.; Dholakia, U.; and Herrmann, A. The social influence of brand community: Evidence from European car clubs. Journal of Marketing, 69, 3 (2005), 19-34.

3. Arakji, R.; and Lang, K. Digital consumer networks and producer-consumer collaboration: Innovation and product development in the video game industry. Journal of Management Information Systems, 24, 2 (2007), 195-219.

4. Arazy, O.; and Gellatly, I.R. Corporate Wikis: The effects of owners' motivation and behavior on group members' engagement. Journal of Management Information Systems, 29, 3 (2012), $87-116$.

5. Baard, P.P.; Deci, E.L.; and Ryan, R.M. Intrinsic need satisfaction: A motivational basis of performance and well-being in two work settings. Journal of Applied Social Psychology, 34, 10 (2004), 2045-2068.

6. Bakker, A.B.; Schaufeli, W.B.; Leiter, M.P.; and Taris, T.W. Work engagement: An emerging concept in occupational health psychology. Work \& Stress, 22, 3 (2008), 187-200.

7. Bargh, J.A.; Chen, M.; and Burrows, L. Automaticity of social behavior: Direct effects of trait construct and stereotype activation on action. Journal of Personality and Social Psychology, 71, 2 (1996), 230-244.

8. Barrick, M.R.; Thurgood, G.R.; Smith, T.A.; and Courtright, S.H. Collective organizational engagement: Linking motivational antecedents, strategic implementation, and firm performance. Academy of Management Journal, 58, 1 (2015), 111-135.

9. Bateman, P.J.; Gray, P.H.; and Butler, B.S. The impact of community commitment on participation in online communities. Information Systems Research, 22, 4 (2011), 841-854.

10. Benlian, A. Web personalization cues and their differential effects on user assessments of website value. Journal of Management Information Systems, 32, 1 (2015), 225-260.

11. Bhattacharya, C.B.; and Sen, S. Consumer-company identification: A framework for understanding consumers' relationships with companies. Journal of Marketing, 67, 2 (2003), $76-88$.

12. Bhattacherjee, A. Understanding information systems continuance: An expectation-confirmation model. MIS Quarterly, 25, 3 (2001), 351-370.

13. Bosch, C.; Sonnentag, S.; and Pinck, A.S. What makes for a good break? A diary study on recovery experiences during lunch break. Journal of Occupational and Organizational Psychology, 91, 1 (2018), 134-157.

14. Burtch, G.; Ghose, A.; and Wattal, S. An empirical examination of peer referrals in online crowdfunding. In Proceedings of the 35th International Conference on Information Systems (ICIS). Association for Information Systems, Auckland, 2014.

15. Chan, T.K.H.; Zheng, X.; Cheung, C.M.K.; Lee, M.K.O.; and Lee, Z.W.Y. Antecedents and consequences of customer engagement in online brand communities. Journal of Marketing Analytics, 2, 2 (2014), 81-97. 
16. Chen, L.; Baird, A.; and Straub, D. Fostering participant health knowledge and attitudes: An econometric study of a chronic disease-focused online health community. Journal of Management Information Systems, 36, 1 (2019), 194-229.

17. Cranefield, J.; Yoong, P.; and Huff, S.L. Rethinking lurking: Invisible leading and following in a knowledge transfer ecosystem. Journal of the Association for Information Systems, 16, 4 (2015), 213-247.

18. Csikszentmihalyi, M. Play and intrinsic rewards. Humanistic Psychology, 15, (1975), 41-63.

19. D’Hooge, S.C.; Hudders, L.; and Cauberghe, V. Direct evaluative conditioning in brand placement: The impact of scene valence and prominence on brand placement repetition effects. Journal of Consumer Behaviour, 16, 5 (2017), 452-462.

20. Deci, E.L.; and Ryan, R.M. The general causality orientations scale: Self-determination in personality. Journal of Research in Personality, 19, 2 (1985), 109-134.

21. Deci, E.L.; and Ryan, R.M. The "what" and "why" of goal pursuits: Human needs and the selfdetermination of behavior. Psychological Inquiry, 11, 4 (2000), 227-268.

22. Deci, E.L.; and Ryan, R.M. Self-determination research: Reflections and future directions. In E.L. Deci and R.M. Ryan, eds., Handbook on Self-Determination Research. University of Rochester Press, Rochester, NY, 2002, pp. 431-441.

23. Deci, E.L.; Ryan, R.M.; Gagné, M.; Leone, D.R.; Usunov, J.; and Kornazheva, B.P. Need satisfaction, motivation, and well-being in the work organizations of a former eastern bloc country: A cross-cultural study of self-determination. Personality and Social Psychology Bulletin, 27, 8 (2001), 930-942.

24. Ghose, A.; Goldfarb, A.; and Han, S.P. How is the mobile Internet different? Search costs and local activities. Information Systems Research, 24, 3 (2012), 613-631.

25. Gill-Simmen, L.; Macinnis, D.; Eisingerich, A.; and Park, C.W. Brand-self connections and brand prominence as drivers of employee brand attachment. Academy of Marketing Science Review, 8, (2018), 128-146.

26. Goh, J.; Gao, G.; and Agarwal, R. The creation of social value: Can an online health community reduce rural-urban health disparities? MIS Quarterly, 40, 1 (2016), 247-263.

27. Haas, M.R.; Criscuolo, P.; and George, G. Which problems to solve? Online knowledge sharing and attention allocation in organizations. Academy of Management Journal, 58, 3 (2015), 680-711.

28. Han, Y.J.; Nunes, J.C.; and Drèze, X. Signaling status with luxury goods: The role of brand prominence. Journal of Marketing, 74, 4 (2010), 15-30.

29. Hann, I.-H.; Roberts, J.A.; and Slaughter, S.A. All are not equal: An examination of the economic returns to different forms of participation in open source software communities. Information Systems Research, 24, 3 (April 2013), 520-538.

30. Hsiu-Yu, H.; and Hao-Te, L. The rosy side and the blue side of emotional brand attachment. Journal of Consumer Behaviour, 17, 3 (2018), 302-312.

31. Johnson, S.L.; Faraj, S.; and Kudaravalli, S. Emergence of power laws in online communities: The role of social mechanisms and preferential attachment. MIS Quarterly, 38, 3 (2014), 795-808.

32. Jöreskog, K.; and Sörbom, A. LISREL 8.80. Skokie: Scientific Software International Inc., Chicago, IL, 2006.

33. Kahn, W.A. Psychological conditions of personal engagement and disengagement at work. Academy of Management Journal, 33, 4 (1990), 692-724.

34. Kankanhalli, A.; Tan, B.C.Y.; and Wei, K.-K. Contributing knowledge to electronic knowledge prepostories: An empirical investigation. MIS Quarterly, 29, 1 (2005), 113-143.

35. Karlan, D.; Mcconnell, M.; Mullainathan, S.; and Zinman, J. Getting to the top of mind: How reminders increase saving. Management Science, 62, 12 (2016), 3393-3411.

36. Khansa, L.; Ma, X.; Liginlal, D.; and Kim, S.S. Understanding members' active participation in online question-and-answer communities: A theory and empirical analysis. Journal of Management Information Systems, 32, 2 (2015), 162-203. 
37. Kim, H.W.; Chan, H.C.; and Kankanhalli, A. What motivates people to purchase digital items on virtual community websites? The desire for online self-presentation. Information Systems Research, 23, 4 (2012), 1232-1245.

38. Kim, S.S. The integrative framework of technology use: An extension and test. MIS Quarterly, 33, 3 (2009), 513-537.

39. Kim, S.S.; and Son, J.-Y. Out of dedication or constraint? A dual model of post-adoption phenomena and its empirical test in the context of online services. MIS Quarterly, 33, 1 (2009), 49-70.

40. Kowal, J.; and Fortier, M.S. Motivational determinants of flow: Contributions from self-determination theory. The Journal of Social Psychology, 139, 3 (1999), 355-368.

41. Kuang, L.; Huang, N.; Hong, Y.; and Yan, Z. Spillover effects of financial incentives on non-incentivized user engagement: Evidence from an online knowledge exchange platform. Journal of Management Information Systems, 36, 1 (2019), 289-320.

42. Kuem, J.; Ray, S.; Siponen, M.; and Kim, S.S. What leads to prosocial behaviors on social networking services: A tripartite model. Journal of Management Information Systems, 34, 1 (2017), 40-70.

43. Kumar, N.; Venugopal, D.; Qiu, L.; and Kumar, S. Detecting review manipulation on online platforms with hierarchical supervised learning. Journal of Management Information Systems, 35, 1 (2018), 350-380.

44. Kumar, V.; and Pansari, A. Competitive advantage through engagement. Journal of Marketing Research, 53, 4 (2016), 497-514.

45. Lee, H.C.B.; Ba, S.; Li, X.; and Stallaert, J. Salience bias in crowdsourcing contests. Information Systems Research, 29, 2 (June 2018), 401-418.

46. Leimeister, J.M.; Huber, M.; Bretschneider, U.; and Krcmar, H. Leveraging crowdsourcing: Activation-supporting components for IT-based ideas competition. Journal of Management Information Systems, 26, 1 (2009), 197-224.

47. Lepper, M.R.; and Henderlong, J. Turning "play" into "work" and "work" into "play": 25 years of research on intrinsic versus extrinsic motivation. In Intrinsic and Extrinsic mMotivation: The Search for Optimal Motivation and Performance. Academic Press, San Diego, CA, US, 2000, pp. 257-307.

48. Limayem, M.; Hirt, S.G.; and Cheung, C.M.K. How habit limits the predictive power of intention: The case of information systems Continuance. MIS Quarterly, 31, 4 (2007), 705-737.

49. Lin, H.F. Effects of extrinsic and intrinsic motivation on employee knowledge sharing intentions. Journal of Information Science, 33, 2 (2007), 135-149.

50. Liu, D.; Santhanam, R.; and Webster, J. Toward meaningful engagement: A framework for design and research of gamified information systems. MIS Quarterly, 41, 4 (2017), 1011-1034.

51. Luo, C.; Luo, X. (Robert); Xu, Y.; Warkentin, M.; and Sia, C.L. Examining the moderating role of sense of membership in online review evaluations. Information \& Management, 52, 3 (2015), 305-316.

52. Ma, M.; and Agarwal, R. Through a glass darkly: Information technology design, identity verification, and knowledge contribution in online communities. Information Systems Research, 18, 1 (2007), 42-67.

53. Ma, X.; Khansa, L.; Deng, Y.; and Kim, S.S. Impact of prior reviews on the subsequent review process in reputation systems. Journal of Management Information Systems, 30, 3 (2013), 279-310.

54. Ma, X.; Khansa, L.; and Hou, J. Toward a contextual theory of turnover intention in online crowdworking. In Proceedings of the 37th International Conference on Information Systems (ICIS). Association for Information Systems, Dublin, Ireland, 2016.

55. Ma, X.; Khansa, L.; and Kim, S.S. Active community participation and crowdworking turnover: A longitudinal model and empirical test of three mechanisms. Journal of Management Information Systems, 35, 4 (2018), 1-34. 
56. Malhotra, N.K.; Kim, S.S.; and Patil, A. Common method variance in IS research: A comparison of alternative approaches and a reanalysis of past research. Management Science, 52, 12 (2006), 1865-1883.

57. McAlexander, J.H.; Schouten, J.W.; Koenig, H.F.; Hardy-Vallee, B.; and Koenig, H.F. Building brand community. Journal of Marketing, 66, (2002), 38-54.

58. McGee, G.W.; and Ford, R.C. Two (or more?) dimensions of organizational commitment: Reexamination of the affective and continuance commitment scales. Journal of Applied Psychology, 72, 4 (1987), 638-641.

59. Mencl, J.; and May, D.R. The effects of proximity and empathy on ethical decision-making: An exploratory investigation. Journal of Business Ethics, 85, 2 (2009), 201-226.

60. Meyer, J.P.; Allen, N.J.; and Gellatly, I.R. Affective and continuance commitment to the organization: Evaluation of measures and analysis of concurrent and time-lagged relations. Journal of Applied Psychology, 75, 6 (1990), 710-720.

61. Mithas, S.; Ramasubbu, N.; Krishnan, M.S.; and Fornell, C. Designing web sites for customer loyalty across business domains: A multilevel analysis. Journal of Management Information Systems, 23, 3 (2006), 97-127.

62. Morhart, F.M.; Herzog, W.; and Tomczak, T. Brand-specific leadership: Turning employees into brand champions. Journal of Marketing, 73, 5 (2009), 122-142.

63. Muñiz Jr., A.M.; and Schau, H.J. Religiosity in the abandoned Apple Newton brand community. Journal of Consumer Research, 31, 4 (2005), 737-747.

64. Osterloh, M.; and Frey, B.S. Motivation, knowledge transfer, and organizational forms. Organization Science, 11, 5 (2000), 538-550.

65. Pan, Z.; Lu, Y.; Wang, B.; and Chau, P.Y.K. Who do you think you are? Common and differential effects of social self-identity on social media usage. Journal of Management Information Systems, 34, 1 (2017), 71-101.

66. Park, C.W.; Eisingerich, A.B.; and Park, J.W. Attachment-aversion (AA) model of customerbrand relationships. Journal of Consumer Psychology, 23, 2 (2013), 229-248.

67. Park, C.W.; MacInnis, D.J.; Priester, J.; Eisingerich, A.B.; and Iacobucci, D. Brand attachment and brand attitude strength: Conceptual and empirical differentiation of two critical brand equity drivers. Journal of Marketing, 74, 6 (2010), 1-17.

68. Phang, C.W.; Kankanhalli, A.; and Tan, B.C.Y. What motivates contributors vs. lurkers? An investigation of online feedback forums. Information Systems Research, 26, 4 (2015), 773-792.

69. Phua, J.; Jin, S.V.; and Kim, J. (Jay). Gratifications of using Facebook, Twitter, Instagram, or Snapchatto follow brands: The moderating effect of social comparison, trust, tie strength, and network homophily on brand engagement, brand commitment, and membership intention. Telematics and Informatics, 34, 1 (2017), 412-424.

70. Ray, S.; Kim, S.S.; and Morris, J.G. The central role of engagement in online communities. Information Systems Research, 25, 3 (2014), 528-546.

71. Rich, B.L.; Lepine, J.A.; and Crawford, E.R. Job engagement: Antecedents and effects on job performance. Academy of Management Journal, 53, 3 (2010), 617-635.

72. Roberts, J.A.; Hann, I.-H.; and Slaughter, S.A. Understanding the motivations, participation, and performance of open source software developers: A longitudinal study of the Apache projects. Management Science, 52, 7 (2006), 984-999.

73. Schultz, S.E.; Kleine, R.E.; and Kernan, J.B. "These are a few of my favorite things" toward an explication of attachment as a consumer behavior construct. Advances in Consumer Research, 16, (1989), 359-366.

74. Shen, W.; Hu, Y.J.; and Rees Ulmer, J. Competing for attention: An empirical study of online reviewers' strategic behavior. MIS Quarterly, 39, 3 (2015), 683-696.

75. Smith, A.; and Anderson, M. Social media use 2018: Demographics and statistics. Pew Research Center, 2018. Available at: https://www.pewinternet.org/2018/03/01/social-mediause-in-2018/(accessed on November 18, 2018).

76. Steers, R.M.; and Porter, L.W. Employee commitment to organizations. In R.M. Steers and L.W. Porter, eds., Motivation and work behavior. McGraw-Hill, New York, 1983, pp. 441-451. 
77. Suh, A.; Cheung, C.M.K.; Ahuja, M.; and Wagner, C. Gamification in the workplace: The central role of the aesthetic experience. Journal of Management Information Systems, 34, 1 (2017), 268-305.

78. Sun, Y.; Lim, K.H.; Peng, J.Z.; Jiang, C.; and Chen, X. Why and when will banner blindness occur? An analysis based on the dual processing theory. In Proceedings of the 14th Americas Conference on Information Systems (AMCIS). Association for Information Systems, Toronto, ON, Canada, 2008.

79. Thomson, M. Human brands: Investigating antecedents to consumers' strong attachments to celebrities. Journal of Marketing, 70, 3 (2006), 104-119.

80. Thomson, M.; MacInnis, D.J.; and Park, C.W. The ties that bind: Measuring the strength of customers' emotional attachment to brands. Journal of Consumer Psychology, 15, 1 (2005), 77-91.

81. Tigert, D.J.; Ring, L.J.; and King, C.W. Fashion involvement and buying behavior: A methodological study. Advances in Consumer Behavior, 3, 1 (1976), 46-52.

82. Trépanier, S.-G.; Fernet, C.; and Austin, S. Workplace bullying and psychological health at work: The mediating role of satisfaction of needs for autonomy, competence and relatedness. Work \& Stress, 27, 2 (2013), 123-140.

83. Tsai, H.; and Bagozzi, R.P. Contribution behavior in virtual communities: Cognitive, emotional, and social influences. MIS Quarterly, 38, 1 (2014), 143-163.

84. Wasko, M.M.; and Faraj, S. Why should I share? Examining social capital and knowledge contribution in electronic network of practice. MIS Quarterly, 29, 1 (2005), 35-57.

85. Xu, Y.; Kim, H.-W.; and Kankanhalli, A. Task and social information seeking: Whom do we prefer and whom do we approach? Journal of Management Information Systems, 27, 3 (2010), 211-240.

86. Yan, L.; and Tan, Y. Feeling blue? Go online: An empirical study of social support among patients. Information Systems Research, 25, 4 (2014), 690-709.

87. Yi, C.; Jiang, Z.J.; and Benbasat, I. Enticing and engaging consumers via online product presentations: The effects of restricted interaction design. Journal of Management Information Systems, 31, 4 (2015), 213-242.

88. Yoon, C.; and Rolland, E. Knowledge-sharing in virtual communities: Familiarity, anonymity and self-determination theory. Behaviour \& Information Technology, 31, 11 (2012), 1133-1143.

89. Zahedi, F. "Mariam"; and Bansal, G. Cultural signifiers of Web site images. Journal of Management Information Systems, 28, 1 (2011), 147-200.

90. Zhang, C.; Hahn, J.; and De, P. Continued participation in online innovation communities: Does community response matter equally for everyone? Information Systems Research, 24, 4 (2013), 1112-1130.

91. Zhang, T.T.; Wang, W.Y.C.; Lin, Y.C.; and Tai, L.-H. Understanding user motivation for evaluating online content: A self-determination theory perspective. Behaviour \& Information Technology, 34, 5 (2015), 479-491.

92. Zhang, Y. Understanding the sustained use of online health communities from a self-determination perspective. Journal of the American Society for Information Science and Technology, 67, 12 (2016), 2842-2857.

93. Zhao, L.; Detlor, B.; and Connelly, C.E. Sharing knowledge in social Q\&A sites: The unintended consequences of extrinsic motivation. Journal of Management Information Systems, 33, 1 (2016), 70-100.

94. Zhou, Z.; Fang, Y.; Vogel, D.R.; Jin, X.-L.; and Zhang, X. Attracted to or locked in? Predicting continuance intention in social virtual world services. Journal of Management Information Systems, 29, 1 (2012), 273-306.

95. Zhu, K. The complementarity of information technology infrastructure and e-commerce capability: A resource-based assessment of their business value. Journal of Management Information Systems, 21, 1 (2004), 167-202. 


\section{About the Authors}

Jungwon Kuem (jkuem@albany.edu) is an Assistant Professor of Information Technology Management in the School of Business at the State University of New York-Albany. She holds a Ph.D. in Computer Science and Information Systems from the University of Jyväskylä, Finland and a Ph.D. in Operations and Information Management from the University of WisconsinMadison. Dr. Kuem's research interests include information security, phishing, cyberloafing, online communities, and smartphone addiction.

Lara Khansa (larak@vt.edu; corresponding author) is the Associate Dean for Undergraduate Programs and a Professor of Business Information Technology in the Pamplin College of Business at Virginia Tech. She received her Ph.D. in Information Systems from the University of Wisconsin-Madison. Dr. Khansa's scholarly activities lie where knowledge of technological artifacts and knowledge of human behavior meet. She works to elucidate the complex interactions between manmade technological creations and real-world social ecosystems. She has published numerous articles in such journals as Journal of Management Information Systems, Journal of Operations Management, Decision Sciences, and Communications of the ACM.

Sung S. Kim (skim@bus.wisc.edu) is the Peter T. Allen Professor in the Department of Operations and Information Management at the Wisconsin School of Business. He holds a Ph.D. in Information Technology Management from the Georgia Institute of Technology. Dr. Kim's research covers online user behavior, including habit, addiction, loyalty, switching costs, information privacy and security, gaming, community participation, and social networking. His work has appeared in Information Systems Research, Journal of Management Information Systems, MIS Quarterly, Management Science, Journal of the Association for Information Systems, and Decision Sciences. 